\title{
The Future of Marketing Chinese Luxury Brands:
} An Analysis of Current Consumer Behavior and Future Implications

\author{
Jun Liang Li ${ }^{1, \mathrm{a}, \dagger}$, Wenxi $\mathrm{Li}^{2, \mathrm{~b}, \dagger}$, Zeyang Wang ${ }^{3, \mathrm{c}, \dagger}$, Ziwei Wang ${ }^{4, \mathrm{~d}, \dagger}$, Xinyao

$$
\text { Zhang }{ }^{5, \mathrm{e}, \dagger}
$$

${ }^{1}$ College of Letters and Science, University of California, Los Angeles

${ }^{2}$ Emory College of Arts and Sciences, Emory University

${ }^{3}$ Farmer School of Business, Miami University

${ }^{4}$ Thurgood Marshall College, University of California, San Diego

${ }^{5}$ Westlake Girls' High School

ajunliangli@ucla.edu, ${ }^{b}$ michelle.li@emory.edu, ${ }^{c}$ wangz257@miamioh.edu, ${ }^{d}$ ziw041@ucsd.edu, 20439@my.westlakegirls.school.nz.

*Corresponding author.Email: michelle.li@emory.edu

These authors contributed equally.

\begin{abstract}
Mainland China has seen significant expansion in its luxury goods market over the past decade and is on track to become the world's largest luxury consumer by 2025 . Understanding the most current consumption patterns of Chinese luxury consumers is pertinent to brand success in China. The purpose of this paper is to examine how domestic luxury brands can optimize their marketing strategies to better adapt to the Chinese luxury market, which foreign brands now dominate. This study analyses the market's consumer behaviour and business strategy through three research designs: (1) The literature research approach is used to analyse Chinese consumer behaviours. The result shows a growing trend of digitalization and preference for domestic brands in recent years. Furthermore, the digitalization trend also reveals the bandwagon effect, where consumers purchase a certain brand to establish their sense of belonging to a designated group. (2) The case study approach analyses luxury brands Shanghai Tang and Louis Vuitton to gain insights on business strategies. Shanghai Tang succeeded from its focus on customer experience but suffered from ambiguous brand positioning. Meanwhile, LV could take advantage of social media platforms such as Xiaohongshu to align with current trends. (3) Using summary and induction, three strategies are suggested for domestic luxury brands: introducing dailylife products, brand-specific customer demand assessments, and digitalization. This study's findings fill the gap for the lack of understanding in regards to luxury Chinese fashion brands. The result provides insight into the current Chinese luxury market and marketing strategies, which can be adapted by both domestic and foreign brands.
\end{abstract}

Keywords: Luxury brand, Chinese market, Consumer behaviour, Marketing strategy

\section{INTRODUCTION}

Mainland China's unprecedented economic growth in the last decades has paved the way for the rapid expansion of its luxury goods market. According to an industry report by Bain \& Company, while the global luxury market declined by $23 \%$ in 2020 , China's market is expected to achieve a $48 \%$ growth, totalling 346 billion RMB [1]. Although international travel restrictions partly fuel this growth due to COVID-19, China's luxury market is expected to continue expanding even after restrictions ease. Furthermore, Bain predicts that China will claim the world's largest share of the luxury market by 2025 [1]. As suggested in McKinsey \& Company's China Luxury Report 2019, this future growth will mainly be driven by the explosion of China's upper-middle class, whose population will rise by $28 \%$ annually [2].

Complimenting China's economic and technological growth, a new consumption pattern is also emerging. As noted in Bain's report, new Millennials and Generation- $Z$ consumers place greater emphasis on "pursuit of fashion" rather than using the luxury goods as an identity statement [1]. Meanwhile, consumers are gathering more 
information from digital sources, which shape their purchasing patterns. Moreover, China recently proposed to develop its economy based on China's domestic circulation, while consumption is one of the "troikas" that stimulate China's GDP development. It is expected that new policy benefits, such as the Hainan's Duty-Free Zone, will further stimulate domestic consumption. These changes promise great potential for luxury brands in China if they could adapt to China's vast yet dynamic market.

In recent years, there have been multiple researches conducted in regard to the understanding of the Chinese luxury market. According to Bain Consulting data, the Chinese luxury goods market has become the primary market for global luxury goods sales [1]. Research findings show that the emergence of new development models in online purchase channels and offline channels is determined by the market rather than by luxury goods companies [3]. The digital environment and changes in online consumption channels are tools to help salespeople study the Chinese market [4]. Therefore, to gain more market share and consumer groups in the Chinese luxury goods market, international luxury brands have vigorously developed integration with China's WeChat. Based on the high amount of daily usage of WeChat per capita, WeChat third-party miniprograms have become an effective communication method between online brand owners and consumers and are even better than traditional overseas fashion luxury methods sales [5]. Besides, with the rapid development of new online shopping and online celebrity sales models in China, China is expected to reach an industry scale of more than RMB 400 billion in 2022 [2]. China's development in new 3D fitting online shopping has become a new sales trend in today's fashion industry [6]. Even when COVID-19 negatively impacted the Chinese market and the global economy, there was no concern over the economic recovery of the Chinese luxury goods market [7].

The consumption behaviour of Chinese consumers is changing. Chinese millennials and Generation- $Z$ consumers have become the main consumer groups in China's luxury consumer market [2]. Chinese millennials and Generation- $Z$ consumption behaviour gradually dominated the Chinese luxury goods sales market. Also, Chinese consumers' consumption concept is changing from Conspicuous consumption to conscious consumerism or rational consumption [7]. For example, Chinese consumers pay more attention to their self-image, and society gives luxury values and luxury functionality [8].

Nevertheless, current research mainly focuses on foreign luxury brands in China; despite the emergence of domestic luxury brands, there is little information and research. Specifically, there is limited information on the business approaches that can be taken by Chinese luxury brands to better adapt to the domestic market.

This research examines how corporate marketing strategies can be optimized in relation to consumers' luxury clothing consumption behaviour in the Chinese market. As millennials and Generation-Z's consumption concepts evolve from a focus of personal wealth and strength to a more rational and attention-to-detail conception regarding the quality of brands and products, current research on corporate marketing strategies are too narrowly focused on foreign luxury brands in China. Therefore, this research will bridge the gap by analysing how the emerging domestic luxury brands driven by the explosive growth of China's upper-middle class can better utilize marketing approaches to smoothly adapt to the domestic market. Namely, there are two main factors to consider while examining this gap: business strategy, specifically in marketing, and Chinese consumer behaviour. Three research designs are chosen to comprehensively understand and analyse these two factors: literature research, case study, and summary and induction. These approaches allow for an in-depth, qualitative breakdown of how domestic companies can optimize their marketing strategies tailored to consumer behaviour.

\section{METHODOLOGY}

The three chosen approaches-literature research, case study, and summary and induction-allow for an in-depth, qualitative breakdown of how domestic companies can optimize their marketing strategies tailored to consumer behaviour. Firstly, literature research is a nonexperimental qualitative review design to reveal known phenomena and trends in the market. Literature research can be obtained through different sources such as books and journals. Reading journals on research and analysis on the Chinese consumers will help analyze the correlations between Chinese consumers' behaviours and the marketing strategy of domestic luxury brands. This approach is crucial for analysing Chinese consumers' behavioural characteristics as it allows for an understanding of the current situation through secondary data collection.

Secondly, this research will also utilize a case study approach that analyzes and examines cases within the real-world context. Case studies are also often used in scenarios where the research is relevantly new, and the result of the case study is used to enhance generalizations. According to Robert Yin, an American social scientist, "Case studies can be done using either qualitative or quantitative evidence. The evidence may come from fieldwork, archival records, verbal reports, observations, or any combination of these" [9]. Therefore, to further specify the case study method utilized in this research, the approach chosen is a qualitative and quantitative observational case study. In this context, Shanghai Tang 
and LVMH, domestic and international luxury brands, are chosen to further investigate marketing strategies' insights and be optimized for current consumer consumption behaviours. A case study examination allows this research to be more applicable and holistic, essential for future applications.

Finally, a summary and induction research method takes the observations and analysis from literature research and case study to a more general set of propositions. Literature research and case studies provide crucial information targeted towards understanding Chinese consumers' behavioural characteristics and the marketing strategy of domestic luxury brands. However, this information must be organized and interpreted through a summary and induction approach, which helps to derive the best marketing strategies for domestic luxury brands accordingly. This method is used to work towards a conclusion, i.e., Why are these studies significant? What should be expected after reading these articles and cases? In this research specifically, this approach will illustrate consumers' general behavioral characteristics, which is essential in understanding the impact that corporate marketing strategy has on consumers' behaviour in luxury clothing consumption.

\section{RESULT}

\subsection{Analysis of Chinese consumers' consumption behavior in purchasing foreign luxury goods}

\subsubsection{Definition of Luxury Goods}

In this study's scope, luxury goods are defined as apparel, cosmetics, and jewellery products with the high brand image, service quality, and prices. In the context of economics, the luxury goods investigated in this paper can often be classified as Veblen goods, where demand for the good increases as price increases. The product may be viewed as a status symbol and become more desirable when the price is higher.

\subsubsection{New Patterns in Digitalization And Bandwagon Effect}

In recent years, studies reveal that Chinese luxury consumers are increasingly defined by digitalization and the "bandwagon effect." According to a study by Rovai, the "New Chinese young digitally-savvy middle-class ... have become one of the main consumers' segments," driving brands to instil their online presence through digitalization [10]. The current trend has shown that digitalization has become a key component that influences consumer's brand choices. Further study has revealed WeChat as a key platform for luxury communication, and that brand exposure on social media does not erode its exclusivity [11]. Since WeChat is a platform that integrates various lifestyle functions and is the preferred way of communication in China, WeChat can aid the development of existing brands but be a starting point for smaller new brands [11]. In addition, with the rise of social media, Chinese consumers are becoming more brand conscious; the "bandwagon effect," where consumers buy a product to establish a sense of belonging to a specific group, has become increasingly pronounced [12]. Consumers would often choose brands whose value they align with and is associated with the group they believe they belong to.

\subsubsection{Increasing Preference for Domestic Brands}

Although Chinese consumers traditionally viewed foreign brands positively, the China Consumer Report 2020 by McKinsey found this trend to be shifting. The consumer survey showed that "respondents ... had a clear preference for Chinese brands over foreign ones in 13 out of 19 categories" for lifestyle products [13]. Moreover, the report indicated that "consumers are also likely to pick local brands for more expensive premium products," such as "higher-end digital devices, skincare, cosmetics, and red wine" [13]. There is also a growing preference for local designer brands, such as Ms. Min, Ming Ma, and Angle Chen. These fashion brands are domestically designed and globally showcased with top foreign brands [13]. This shifting pattern indicates Chinese consumer's growing preference for brands that echo their culture and tradition.

\subsection{Case Analysis Of Marketing Strategies Of Foreign And Domestic Luxury Brands}

A luxury brand's success in the development process is accompanied by a comprehensive analysis of the luxury brand market, including an accurate analysis of luxury consumers' consumption behavior characteristics. Luxury brands need to formulate marketing strategies suitable for their development based on the market's existing characteristics and problems. Formulating Chinese luxury consumers' marketing strategies requires analysis from multiple aspects of Chinese luxury brands and international luxury brands. Analyzing luxury brands' marketing strategies can reflect China's development in recent decades, including its situation in the international market.

\subsubsection{Chinese Luxury Brand: Shanghai Tang}

The critical factors for Shanghai Tang's success as China's first luxury brand are high-quality products, reasonable prices, its geographic store location, and excellent promotional strategies. Firstly, Shanghai Tang's development needs a long-term stable source of income [14]. Two important strategies to make income sources more stable are to expand consumer groups and increase 
sales. To expand the consumer group, Shanghai Tang changed the target group from one-time consumers to long-term customers. Therefore, Shanghai Tang has designed different clothing styles and accessories to meet Chinese consumers' practical needs in daily life. It is not limited to the products used during festivals, weddings, and other events [14].

Secondly, cost control is an essential key to a company's long-term development. Since Shanghai Tang highly values consumers' shopping experience, its cost of stores exceeds a reasonable range, which has caused the brand to have a capital chain problem [14]. Shanghai Tang's market positioning is premium services and products. As a luxury brand, Shanghai Tang sells highpriced products to consumers, helping the brand obtain higher-profits and promotion with high quality.

Finally, Shanghai Tang promotes the unique cultural value of the brand and promotes consumer shopping demand. Adding Chinese elements such as silk to products can increase the brand's national cultural recognition by Chinese consumers. In the new product promotion activities, Shanghai Tang arranged Chinese models to participate in the show, which perfectly combined products endowed with Chinese culture with Chinese consumers' profile [14].

However, Shanghai Tang's ambiguous positioning of target consumer groups can make it difficult to balance Eastern and Western cultures. According to a 2017 interview, Shanghai Tang tried to reduce its dependence on traditional Chinese styles [15]. In addition, Shanghai Tang's single pursuit of internationalization in the past believes that Westerners' advocacy of exoticism has led to the loss of a large number of Chinese consumers and a $50 \%$ reduction in turnover [14]. Furthermore, Chinese millennials have become the main consumer group in the luxury goods market in recent years. Still, Shanghai Tang's failure to respond to Chinese consumer groups' consumer behavior changes has led to detrimental impacts [15].

\subsubsection{Foreign Luxury Brand: Moët Hennessy- Louis Vuitton (LVMH)}

The emergence of new online consumption models in China's luxury market has led Louis Vuitton (LV), a globalized French luxury goods company, to develop online marketing strategies. LV's official website has formed a high-level service standard that combines order, delivery, and after-sales service in one which has been proven to be effective and successful, as seen from the $8 \%$ of total sales from only nine months between 2018 and 2019 [16]. This new marketing strategy played an important role in COVID-19 lockdowns. When COVID19 affected the global economy, China, as the first market to resume normal operations, increased LV's revenue by more than $65 \%$ in the second quarter of 2020 [17]. In addition, LV can target more user groups and attention through marketing and publicity methods combined with APP. In 2019, LV enhanced consumer interaction through creating mini-programs and online stores on WeChat and improved online stores' consumption experience based on user feedback [16]. LV's development on social media networks also plays a role in brand promotion. LV gained more than 4.5 million fans' attention and support by creating official accounts on the Xiaohongshu APP and Weibo website. In 2018, LV touch was launched and embedded in iMessage to be more integrated into consumers' lives.

Luxury brands combine their own brand's distinctive elements or logos with products of other brands in both similar and different industries to expand consumer groups and provide consumers with different experiences. In 2019, LV cooperated with League of Legends games to launch skin products with LV LOGO in the game, thereby increasing the sales of game-related products and enhancing the game customer experience and its brand awareness [16]. With the emergence of new consumer concepts of millennials and other consumers, changing the presentation of iconic brand logos creatively is an effective marketing strategy [16]. LV redesigned the expression of the new mooncake packaging logo and added the Chinese elements that consumers favour. This new combined marketing strategy has increased the sales of new products [17].

LVMH's promotion activities can further stimulate consumers' desire to shop. LV launched a new perfume series with the prediction that sales can reach 60 million EUR a year and that after the launch, sales will continue to increase by nearly $20 \%$ [18]. The discount campaign for the free refill of the second bottle stimulated consumers' desire to purchase. In the 2017 fiscal year, LVMH's perfume and makeup department's profit reached 42.6 billion EUR, an increase of $13 \%$ over the previous year, making it the category with the most substantial growth of LV [18]. The acquisition of Dior by LVMH Group helped it successfully enter the perfume field's international market, especially the Chinese market. However, COVID-19 caused LVMH's stock price to fall by $19 \%$ in the first half of 2020 [19]. To alleviate the decline in income, $\mathrm{LV}$ tried to obtain higher profits in the Chinese market through a special promotion strategy: increasing the unit price of products. After the official reveal of the plan, LV China's stores' sales surged 50\% year-on-year [19].

Today, the foreign luxury industry occupies a dominant position in the luxury industry [20]. Whether it be a family business or a new brand, joining the stock exchange generally helps the company become more profitable. LVMH successfully went public in the 1980s to expand capital. After the company's return on capital has increased, other companies' acquisition became an inevitable development trend. The M\&A plan is an 
excellent opportunity for the brand to enrich the retail network, production line, and industrial chain. LVMH fills in the gaps in the cosmetics field after acquiring the Dior cosmetics brand.

However, the luxury brand industry faces challenges: one being fake products or counterfeit consumer goods. According to the "2018 Global Brand Counterfeit Report", the total loss globally in 2017 reached 1.2 trillion U.S. dollars, and it is expected to reach 1.82 trillion U.S. dollars by 2020 [21]. LV also faces this problem, especially in the Chinese market. This issue has led to a decline in LV brand value as many consumers choose to purchase the cheaper fake LV products [22]. In addition, because the impact COVID-19 had on the global economy is different from conventional economic crises, the "lipstick effect", which is the theory that consumers are more willing to buy less costly luxury goods during economic crises, did not seem to take effect. Typically, during an economic recession, consumers would buy lower-priced luxury goods such as lipsticks and skincare; however, during COVID-19, everyone needs to wear masks in public places, which led to poor sales of luxury beauty products. In the first two months of 2020, beauty omnichannel sales fell by $13 \%$ [23]. Therefore, the "lipstick effect" did take effect. Overall, while it is inevitable that luxury brands will face challenges, mitigating the detriments and improving marketing strategies can ensure future growth and prosperity.

\section{DISCUSSION}

China's consumption of luxury goods accounts for nearly half of the world's total consumption. According to recent research, China's per capita disposable income has reached 32,189 yuan, which exceeds the minimum standard for consumer luxury accessories [24]. China's vigorous luxury consumer market's purchasing power has had a certain impact on foreign investment in luxury goods. With luxury consumption dropping in 2016 to its lowest level since 2009, much attention has been focused on one of the biggest forces in global luxury spending: Chinese consumers [25]. Therefore, certain improvement strategies can be formulated by optimizing domestic sales plans for domestic luxury brands to increase Chinese goods and services' performance.

\subsection{Strategy I: Quality Daily-Life Products}

From the results of this study, Chinese consumers prefer purchasing locally for premium goods like wine, skincare, etc. Their focus is on the quality and effectiveness of the products; spending more on these goods that are more practical in daily lives makes them feel that they are worthy even at a higher expense. For example, some expensive skincare products that targeted female consumers could cost thousands of RMB. Still, the quality of these products bring out tremendous effects on their skin, such as anti-aging.

Selling practical daily luxury products is also a strategy to retain more long-term customers since they are typically not one-time-purchase products. As Chinese consumers choose domestic luxury brands to buy practical products, Chinese luxury brands can utilize this opportunity to produce practical luxury accessories, especially ones that are exquisite in appearance, easy to carry, and can be used and re-used frequently.

\subsection{Strategy II: Comprehensive Consumer Demand Assessment}

While selling products in China, it is essential for brands to be sensitive and have a comprehensive understanding of Chinese consumers' consumption mentality. Before production, luxury brands must consider the design of the product from various perspectives, including political. This research found that Shanghai Tang had a 50\% loss in consumers and sales because they advocate Western exoticism. However, when their products added Chinese elements, they became more recognized and favoured. Therefore, in the analysis of the behaviours and mentality of Chinese consumers, it can be recognized that they prefer products and brands that advocate for Chinese culture today. Silk, dragon patterns, and other elements that represent the history of China are admired. It is worthwhile for Chinese domestic luxury brands to add these elements to their designs instead of focusing on Western fashion. However, this does not imply that domestic brands should completely change their brand image; instead, it could be a season or collection concept. Furthermore, a creative interpretation of traditional Chinese fashion elements can fit the younger generation's taste since the younger middle-class generation takes a huge proportion of consumers that shop at luxury brands.

\subsection{Strategy III: Technological Integration}

In today's day and age, technology, specifically social media, is an essential part of consumers' daily life. The young middle-class generation that fills the luxury market is especially highly digitized and technologically immersed. Furthermore, during Covid-19 pandemics, online shopping also became popular and handy to many Chinese consumers beyond this generation. Online shopping, which is conducted through websites and APPs, is an essential business element in modern Chinese society, not only convenience but also brand promotion and image. The result can see the impact of going digital of LV's recent technology innovations. Taking customer experience to the next level provides a high-quality online shopping experience through premium service and convenient delivery options. They also implemented their promotions in multiple social media platforms-an 
effective sales plan which helped them grow their profit even during the pandemic-induced global economic recession. As technology plays a huge part in people's lives, online shopping also became a trend because of its convenience. Some brands even create online stores before they have any physical stores to save costs. Since almost everyone in China uses WeChat, a multi-purpose social media platform, domestic luxury brands can easily integrate online shopping by utilizing WeChat's ecommerce platform that promotes and sells their products. However, online shopping also has its unique risks, such as lost packages, website malfunction, order mistakes, and more. These small mistakes can make a great impact on company reviews and damage consumer trust and loyalty. Therefore, as a luxury brand, it is crucial to bring stores online and provide a premium experience for customers, just like in in-person stores.

Through the analysis of Chinese consumer behavior and the case studies of a domestic brand and international luxury brand, Shanghai Tang and LV, three marketing strategies are derived from this research to improve domestic luxury brands' recognition and sales in China. Firstly, domestic brands should consider introducing quality products that are practical and used daily. This research showed that Chinese consumers prefer shopping locally for quality luxury products functional in daily life. Secondly, due to the fast-changing consumer mentality, companies must conduct comprehensive research on Chinese consumers' fashion demand and the recent influences in political, economic, social, and all other perspectives. In recent years, the incorporation of traditional Chinese elements, which showcases Chinese culture, has taken over Chinese consumers' demand, whereas Western fashion used to be the chase. Last but not least, utilizing digitized platforms is a marketing strategy and provides consumers with the convenience and safety of shopping from home after the global pandemic. Chinese consumers are highly technologically immersed in their daily lives, from takeout to online grocery shopping. Ecommerce is hugely influential in the Chinese market. Therefore, domestic luxury brands and any other luxury brands considering entering China should build an online presence, whether it be in the form of a website, APP, or through other platforms such as WeChat. However, it is important to note the quality of online shopping service is equally, if not more, essential as bad customer experiences can lead to damaging consequences. Overall, this research has shown that these strategies are easy-to-implement and are all crucial in building a forward-thinking successful Chinese luxury brand.

\section{CONCLUSION}

This study has thoroughly analyzed trends and patterns of Chinese consumer's behavior in the domestic luxury market. The result bridges the gap that exists in understanding how domestic luxury brands driven by the surge of China's upper-middle class can better utilize marketing approaches to adapt to China's market smoothly. After considering business strategies and Chinese consumer behavior, three marketing strategies have been proposed to better the growth of luxury brands: introducing quality daily-life products, conducting a comprehensive consumer demand assessment, and integrating technological innovations. These strategies are not only forward thinking but have also proven effective in increasing demand and sales for luxury brands, especially in the Chinese market. However, there are limitations.

The strategies are beneficial to the brand, but the cost that comes with it may be detrimental to some-especially smaller brands that have just entered the market with insufficient funding. The research and preparation behind introducing daily life products, the expenditure behind conducting an extensive consumer demand, and the IT support necessary for technological integration are all important cost factors that the company should be aware of. Furthermore, the integration of technology strategy has its own limitation of potentially lowering brand loyalty and trust if the technology is not well-integrated. Consistent website malfunctions, order mistakes, and shipping delays are all seemingly-minor but crucial service factors that consumers highly value.

Despite the limitations, the strategies in a holistic view bring more benefits than detriments. They allow small companies to prepare for a successful launch and offer larger existing companies a new marketing strategy that'll boost their sales and demand. As the market is constantly evolving and consumer demand shifts, new research is needed in the future to ensure the most effective marketing strategy for that time and place. As for now, this research has derived three pretentious strategies that Chinese luxury brands should all consider.

\section{REFERENCES}

[1] Lannes, B., \& Zhang, C. (2020). (rep.). China's Unstoppable 2020 Luxury Market. Bain \& Company and Tmall Luxury Division. Retrieved from https://www.bain.cn/pdfs/202012160134321779.pd f

[2] Luan, L., Kim, A., Zipser, D., Su, M., Lo, A., Chen, C., \& Zhang, C. (2019). (rep.). China Luxury Report 2019. McKinsey Greater China's Apparel, Fashion and Luxury Group. Retrieved from https://www.mckinsey.com/ /media/mckinsey/feat 
ured $\% 20$ insights/china/how $\% 20$ young $\% 20$ chinese $\% 20$ consumers $\% 20$ are $\% 20$ reshaping $\% 20$ global $\% 2$ 0luxury/mckinsey-china-luxury-report-2019-howyoung-chinese-consumers-are-reshaping-globalluxury.ashx

[3] Guercini, S., Ranfagni, S., \& Runfola, A. (2020). Ecommerce internationalization for top luxury fashion brands: some emerging strategic issues. Journal of Management Development, 39(4), 423436. https://doi.org/10.1108/jmd-10-2019-0434

[4] Guercini, S., Milanesi, M., Mir-Bernal, P., \& Runfola, A. (2020). Surfing the Waves of New Marketing in Luxury Fashion: The Case of Online Multi-brand Retailers. Advances in Digital Marketing and ECommerce, 203-210. https://doi.org/10.1007/978-3-030-47595-6_25

[5] Liu, S., Perry, P., \& Gadzinski, G. (2018). The implications of digital marketing on WeChat for luxury fashion brands in China. Journal of Brand Management, 26(4), 395-409. https://doi.org/10.1057/s41262-018-0140-2

[6] Jia, Y., \& Zhang, J. (2019, October 30). Talking about the current situation and problem analysis of $3 \mathrm{D}$ virtual fitting. https://www.fx361.com/page/2019/1030/5931608. shtml.

[7] Roulet, C. (2021). Luxury market expected to grow $15 \%$ in 2021 - FHH Journal. Journal.haute horlogerie.org. Retrieved 20 March 2021, from https://journal.hautehorlogerie.org/en/luxurymarket-expected-to-grow-15-in-2021/.

[8] Faschan, M., Chailan, C., \& Huaman-Ramirez, R. (2020). Emerging adults' luxury fashion brand value perceptions: A cross-cultural comparison between Germany and China. Journal of Global Fashion Marketing, 11(3), 207-231. https://doi.org/10.1080/20932685.2020.1761422

[9] Yin, R. (1981). The Case Study Crisis: Some Answers. Administrative Science Quarterly, 26(1), 58-65. doi: $10.2307 / 2392599$

[10] Rovai, S. (2018). Digitalisation, luxury fashion and "Chineseness": The influence of the Chinese context for luxury brands and the online luxury consumers experience. Journal of Global Fashion Marketing, $\quad 9(2), \quad 116-128$. https://doi.org/10.1080/20932685.2018.1435294

[11] Mainolfi, G. (2020). Exploring materialistic bandwagon behaviour in online fashion consumption: A survey of Chinese luxury consumers. Journal of Business Research, 120, 286293. https://doi.org/10.1016/j.jbusres.2019.11.038.
[12] Ho, J., Poh, F., Zhou, J., \& Zipser, D. (2019). (rep.). China consumer report 2020. Retrieved from https://www.mckinsey.com/ /media/mckinsey/feat ured $\% 20$ insights/china/china $\% 20$ consumer $\% 20$ rep ort $\% 202020 \% 20$ the $\% 20$ many $\% 20$ faces $\% 20$ of $\% 20 t$ he $\% 20$ chinese $\% 20$ consumer/china-consumerreport-2020-vf.ashx

[13] Liu, S., Perry, P., \& Gadzinski, G. (2019). The implications of digital marketing on WeChat for luxury fashion brands in China. Journal of Brand Management, 26(4), 395-409. https://doi.org/10.1057/s41262-018-0140-2

[14] Ooi, J. (2019, August 21). What Shanghai Tang's rise, fall and return means for luxury fashion. Vogue Business.

https://www.voguebusiness.com/fashion/shanghaitang-richemont-chinese-luxury-fashion.

[15] Liu, J. (2017, July 4). These three major problems may have prevented Shanghai Tang from creating a Chinese miracle in the luxury industry. http://www.weartrends.com/a/34740.aspx.

[16] David, M. (2020, February 20). Louis Vuitton in China: The king of luxury brands in China - Daxue Consulting - Market Research China. Louis Vuitton in China: The king of luxury brands in China. https://daxueconsulting.com/louis-vuitton-inchina/.

[17] Booker, A. (2020, October 13). Louis Vuitton, Prada, and Loewe: Three Brands, Three China Content Strategies. Jing Daily. https://jingdaily.com/louisvuitton-prada-loewe-china-content-strategiesbrand/.

[18] Jia, L. (2018, March 14). With eight perfumes released in two years, LV has developed the beauty business rapidly. cosmetic observer. http://www.cosmeticobserver.com/article/content/1 2536 .

[19] Yu, G. (2020, May 18). Luxury promotion depends on price increases, LV price increases lead to domestic retaliatory consumption, and sales increase by $50 \%$. sina. https://k.sina.cn/article_2328665481_8acc9d89001 00rqnb.html.

[20] Donzé, P.-Y. (2018). The Birth of Luxury Big Business: LVMH, Richemont and Kering. Global Luxury, 19-38. https://doi.org/10.1007/978-981-105236-1 2

[21] Yang, T. (2018). (rep.). "Global Brand Counterfeit Report 2018": The total loss caused by global counterfeit goods reached US\$1.2 trillion, and the 
loss of high-end brands was US\$98 billion.

Retrieved from https://luxe.co/post/82717

[22] Wang, X. (2013, October 28). LV China's brand value declines, and counterfeit goods flood. finance.sina.

http://finance.sina.com.cn/chanjing/sdbd/20131028 /052517131448.shtml.

[23] Pen, D. (2020, July 23). "Lipstick effect" failed? Nail polish sales soared by $218 \%$ under the epidemic. hntv.tv. https://www.hntv.tv/yc/article/1/128624209077010 8416. [24] Sheng Huo Bao. (2021, January 18). National Bureau of Statistics of China in 2020, the national per capita disposable income of residents is 32,189 RMB (residents' income). Retrieved from https://www.sohu.com/a/445186301_172952.

[25] Lambert, B. B, D-S., A,K., N,Y. ( 2017, August 16). Chinese Luxury consumers: More global, More demanding, still spend. From https:/www.mckinsey.com/businessfunctions/marketing-and-sales/ourinsights/chinese-luxury-consumers-more-globalmore-demanding-still-spending\#. 